\title{
Beyond Subjective Well-being: A Critical Review of the Stiglitz Report Approach to Subjective Perspectives on Quality of Life
}

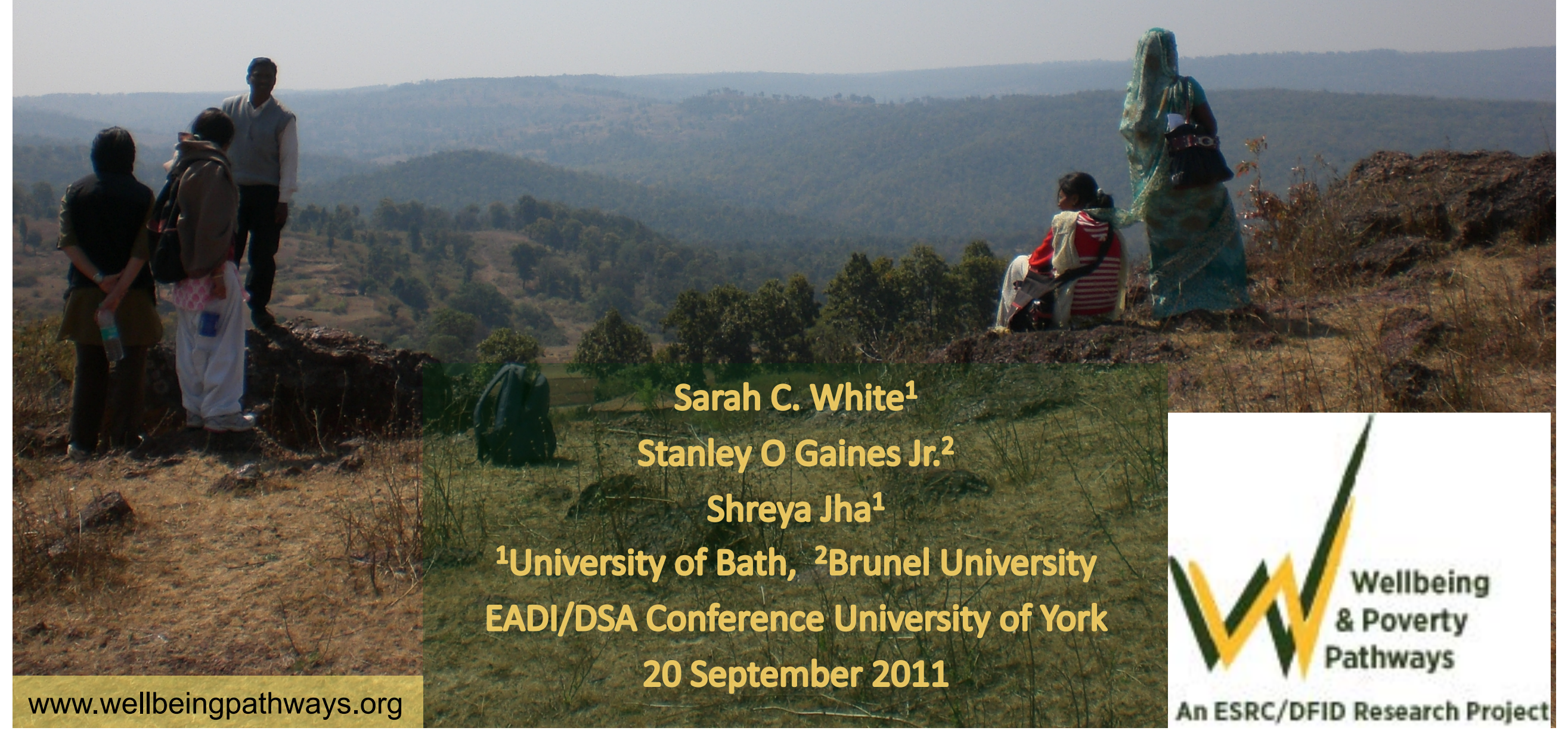




\section{Key intervention}

'Another key message, and unifying theme of the report, is that the time is ripe for our measurement system to shift emphasis from measuring economic production to measuring people's well-being.'

(Stiglitz et al., 2009:12, original emphasis) 


\section{Background}

- Stiglitz report commissioned by President Sarkozy, 2008

- Led by Joseph Stiglitz and Amartya Sen

- Remit to look at alternatives to GDP in measuring national level statistical data about society and economy

- Highly influential: e.g. UK ONS consultation 2011 on what matters to people

- Not that subjective should replace objective - alternative indicator alongside others 


\section{This paper}

- Welcome the way report has strengthened place of wellbeing on international agenda and subjective perspectives on quality of life

- But concern at limited approach that is taken to this, and the potential implications if this is adopted uncritically

- Issues:

- Limited focus

- Methods/measures /concepts

- Universally applicable?

- Politics - including north/south

- Drawing on $1^{\text {st }}$ year of wellbeing pathways research (Zambia, India) 


\section{Subjective well-being: the concept}

- 'Subjective measures of quality of life' identified with subjective wellbeing (SWB) - becomes a quasi domain of its own

- Apparent simplicity: asking people directly about satisfaction and positive/negative emotions ('affect')

- People self-report, so take own values into account

But:

- What is it? A means of measurement that has become reified into a property of persons?

- Synthetic - combination of 2 measures designed for different purposes

- More - or less - than happiness?

- Other approaches, even within psychology, look at functioning and fulfilment - is SWB slim or thin? 


\section{One size fits all?}

Our research suggests cultural and economic context plays a much greater part in shaping both inner wellbeing and the methods used to measure it:

- Cultures of questioning: Abstract and generaised vs specific and tangible

- Indirect vs direct cultures of expression: implications through more general statements: 'the life of a woman!' or stories

- Questions about the future led to response 'who can tell what the future will hold?'

- Many statements about self are difficult: negative statements may be feared to attract the evil eye; comparisons with others may be seen as invidious; professing pride in one's own achievements may be seen as inappropriate 


\section{A new vision of a Global Projection of Subjective Well-being}

\section{the world?}

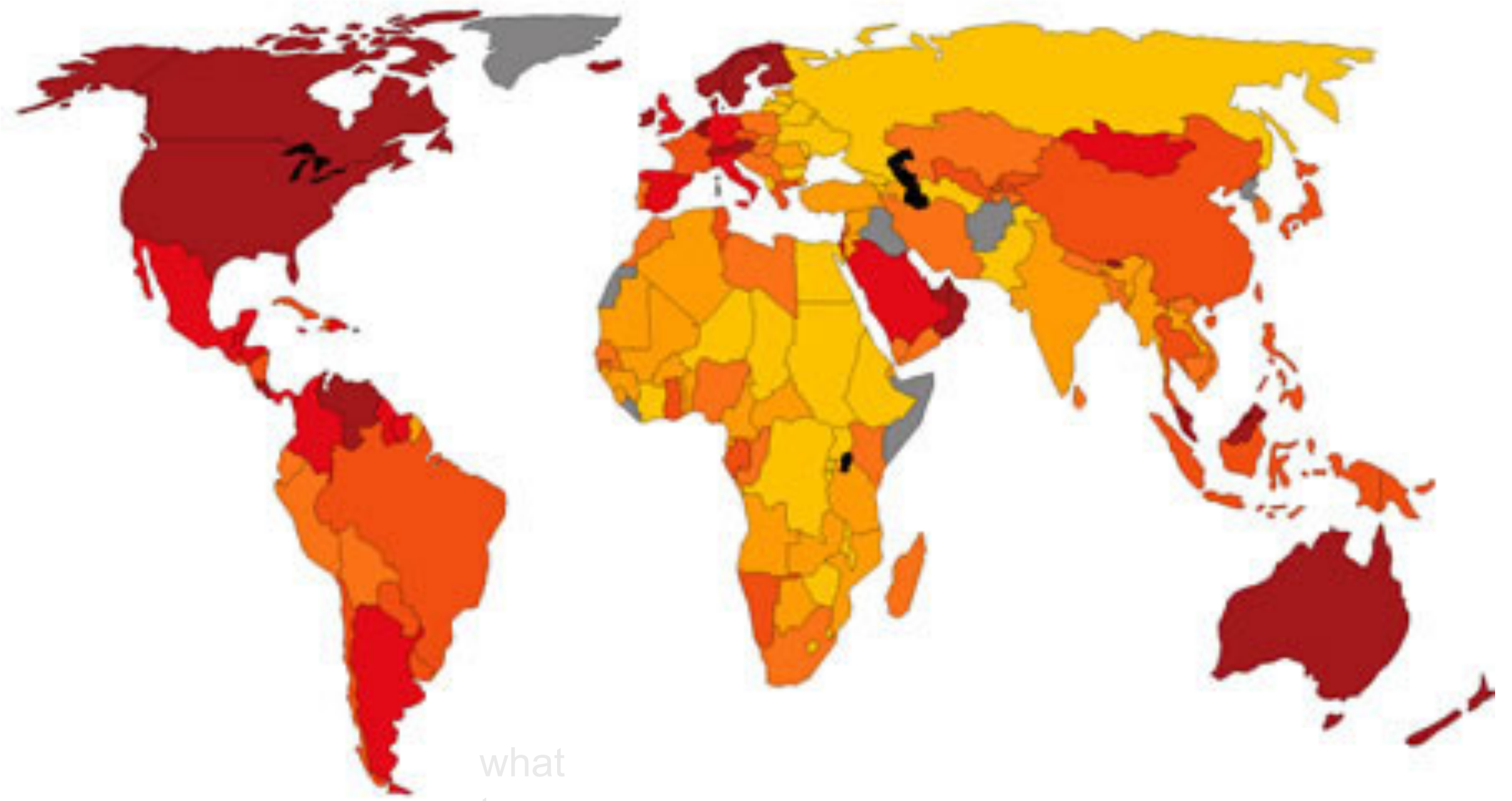

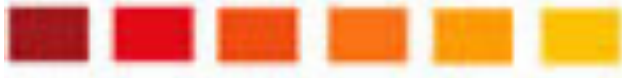

High SWB ..... Low SWB
Adrian White,

University of Leicester, 2007 


\section{Politics of SWB}

- Potential of wellbeing to challenge conventional north-south polarities

- But increasingly SWB used to reinforce them: former Communist and Islamic countries 'quite joyless', Latin America 'high levels of affect'

- Good for development studies (poverty also makes people unhappy)?

- Or dangerous: another axis for the claim of western superiority? 


\section{Conclusion}

- SWB is one way of assessing subjective perspectives, but there are alternatives, even within the psychology literature

- Need to question universality: much more attention needed to cultural bias within the concepts and means of measurement

- Where is the subject in the subjective?

- Is there some collective bad faith in seeking 'objective' evidence from subjective indicators?

- Need assess subjective across domains, not contain it in one

- Need to make space for the qualitative - hear the subaltern speak!

- Watch the politics and reversion to 'West is Best' narrative

See also: www.wellbeingpathways.org 